\title{
Electrical activity of the infundibulum in relation to ovulation in the chicken
}

\author{
K. Shimada and Y. Tanabe \\ Department of Animal Physiology, Nagoya University, Chikusa, Nagoya, Japan 464
}

\begin{abstract}
Summary. Electrical activity was recorded from the smooth muscle layer of the infundibulum of unanaesthetized hens during the ovulation cycle. There were lowfrequency isolated spike potentials throughout the cycle except for the period near ovulation. There were intermittent bursts of spike potentials about $1 \mathrm{~h}$ before ovulation and then an increased frequency of spike potentials near the time of ovulation. These may be related to the activity of the infundibulum engulfing the shed ovum. The frequency of electrical activity tended to decrease shortly after ovulation, but then increased again for a few hours. Premature ovulation induced by progesterone i.m. was associated with similar electrical changes.
\end{abstract}

\section{Introduction}

Engulfing the shed ovum by the infundibulum is one of the most important functions of the oviduct in regard to egg formation. Unlike that of mammals, the avian infundibulum is anatomically more distant from the ovary and the shed ovum is quite large in diameter. It has been suggested that there must be some special co-ordinating mechanisms between the ovary and the oviduct to regulate the engulfing activity of the infundibulum (see Gilbert, 1971). If the infundibulum fails to pick up the shed ovum, internal laying occurs and this results in low egg production. Although Gilbert (1971) reported that the infundibulum becomes active about the time of ovulation there has been little study of the changes in the infundibular activity during the laying cycle. Studies on infundibular motility in vitro have been reported (Chen \& Hawes, 1970; Verma, Prasad \& Slaughter, 1976; Crossley, Ferrando \& Eiler, 1980) but the activity was not correlated with engulfing ability. Crossley, Ayuy \& Ferrando (1975), Talo \& Kekäläinen (1976), Roche \& Brard (1978) and Shimada (1978) have made observations on the avian oviduct in vivo but did not study the infundibulum. The present study was undertaken to examine changes in infundibular motility in relation to engulfing the shed ovum.

\section{Materials and Methods}

Twenty-one crossbred laying hens (Goto 360), 10-14 months old and weighing 2.0-2.6 kg, were maintained in individual cages. The lighting regimen was $14 \mathrm{~h}$ light (06:00-20:00)/24 h and food and water were always available. The oviposition time of individual hens was recorded daily by a microswitch-digital clock assembly. The accuracy of the timing was within 2 min. The surgical procedures for implantation of the bipolar electrodes (needle type) into the smooth muscle of the oviduct were essentially as described previously (Shimada, 1978). The electrodes 
were positioned on the infundibulum $1 \mathrm{~cm}$ caudal to the ostium and on the dorsal caudal uterus (shell gland). A radiotelemetric technique was used for continuous recordings of electrical activity of the infundibulum for several days throughout laying cycles of freely moving hens (Shimada \& Asai, 1978). The occurrence of ovulation within the clutch was confirmed by rectal palpation of the presence of an egg about $7 \mathrm{~h}$ after the time of oviposition of the preceding egg as well as the actual times of oviposition in each hen. To determine the time of ovulation more precisely, electrical activity of the infundibulum and uterus were recorded simultaneously by a direct wire measurement during the dark period following oviposition of the terminal egg $\left(C_{t}\right)$ of the clutch. The time of ovulation of the first egg $\left(C_{1}\right)$ of the clutch was estimated by the frequency peak of uterine electrical activity which was restricted to $1 \mathrm{~h}$ before the $\mathrm{C}_{1}$ ovulation (Shimada \& Asai, 1978; Shimada, 1979). Recordings were made for a total of 45 days in 21 different birds, each hen being observed for 2-10 days. At $14 \mathrm{~h}$ before the $\mathrm{C}_{1}$ ovulation, progesterone $(1.0 \mathrm{mg} / \mathrm{hen}$ : Oophormin luteum, Teikoku-Zoki Pharmaceutical Co., Tokyo) was injected into the breast muscle.

\section{Results}

The implantation of the recording electrodes on the infundibulum frequently resulted in cessation of laying. However, about $50 \%$ of the operated hens eventually resumed a normal laying cycle 1-2 weeks after operation. Birds with irregular ovulatory cycles were not included in the study.

\section{Pattern of electrical activity}

An example of electromyogram of the infundibulum and the uterus is shown in Text-fig. 1. There were 1-4 isolated spike potentials/min for several hours before ovulation in the infundibulum, while the uterus exhibited more frequent activity. About $1 \mathrm{~h}$ before ovulation, the relatively stable activity of the infundibulum was replaced by bursts of spike potentials which occurred intermittently for 10-20 min and were followed by an abrupt increase with relatively regular intervals about 20 min before ovulation. Within a few minutes before ovulation, activity of the infundibulum declined.

\section{Frequency of the infundibular electrical activity during the laying cycle}

The frequency of spike discharges of $\langle 30 \mu \mathrm{V}$ of amplitude per $10 \mathrm{~min}$ was represented as an index of oviducal motility. Text-figure 2 shows the frequency changes in electrical activity of the infundibulum for 6 days in a bird that laid 4 eggs on 4 consecutive days for a clutch which was separated by a single pause day. Shortly before the time of the $C_{1}$ ovulation, marked increases in the frequency of electrical activity were observed (Days 1 and 6 ). There was no increase at the time of oviposition but marked increases were seen shortly after the oviposition when the succeeding ovulations were occurring (Days 2, 3 and 4). The frequency varied with 7 hens examined, but the intermittent occurrences of bursts of spike potentials always preceded by 30-60 min the preovulatory increase in the frequency of electrical activity of the infundibulum in all the hens. However, such a marked increase was not detected after the terminal oviposition which was unaccompanied by ovulation, although the frequency tended to increase slightly. There were also increases in the frequency $1-2 \mathrm{~h}$ after ovulation

The changes in electrical activity of the infundibulum and the uterus during spontaneous ovulation of the first egg of a clutch $\left(C_{1}\right)$ are shown in Text-fig. 3. There was a biphasic pattern of electrical activity in the uterus which is characteristic for the preovulatory period (Shimada \& Asai, 1978), but the frequency of infundibular electrical activity remained low during most of the preovulatory period, sharply increasing to a rate of 90 spike discharges/10 min at $30 \mathrm{~min}$ before 
$5 \mathrm{~h}$

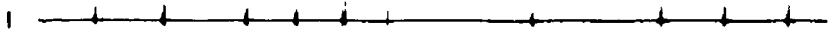

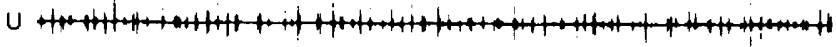

$3 \mathrm{~h}$

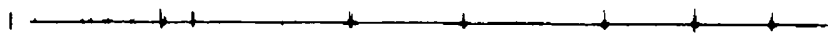

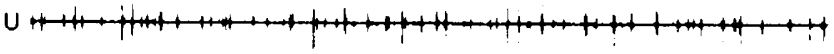

$1 \mathrm{~h}$

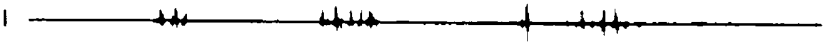

$U$ U
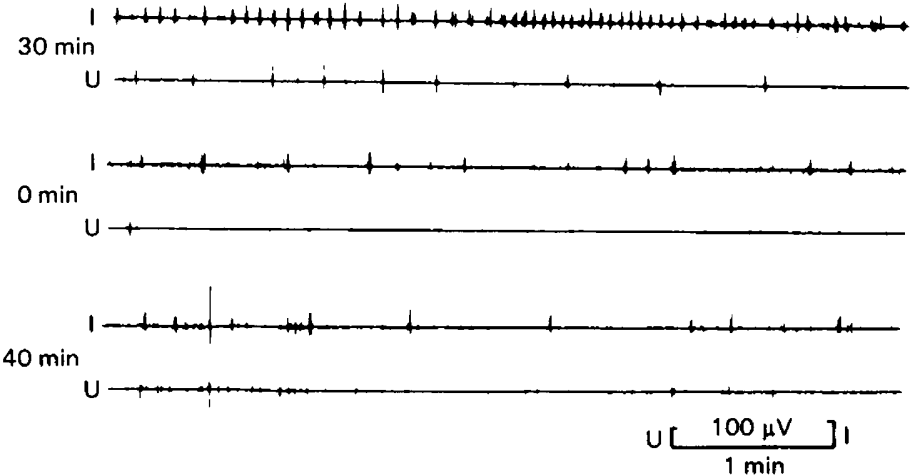

Text-fig. 1. Action potentials of the infundibulum (I) and the uterus (U) or shell gland during the period from $5 \mathrm{~h}$ before ovulation of the first egg of a clutch to $40 \mathrm{~min}$ after the ovulation $(08: 26 \mathrm{~h})$. The terminal egg of the previous clutch was at 15:59 h.
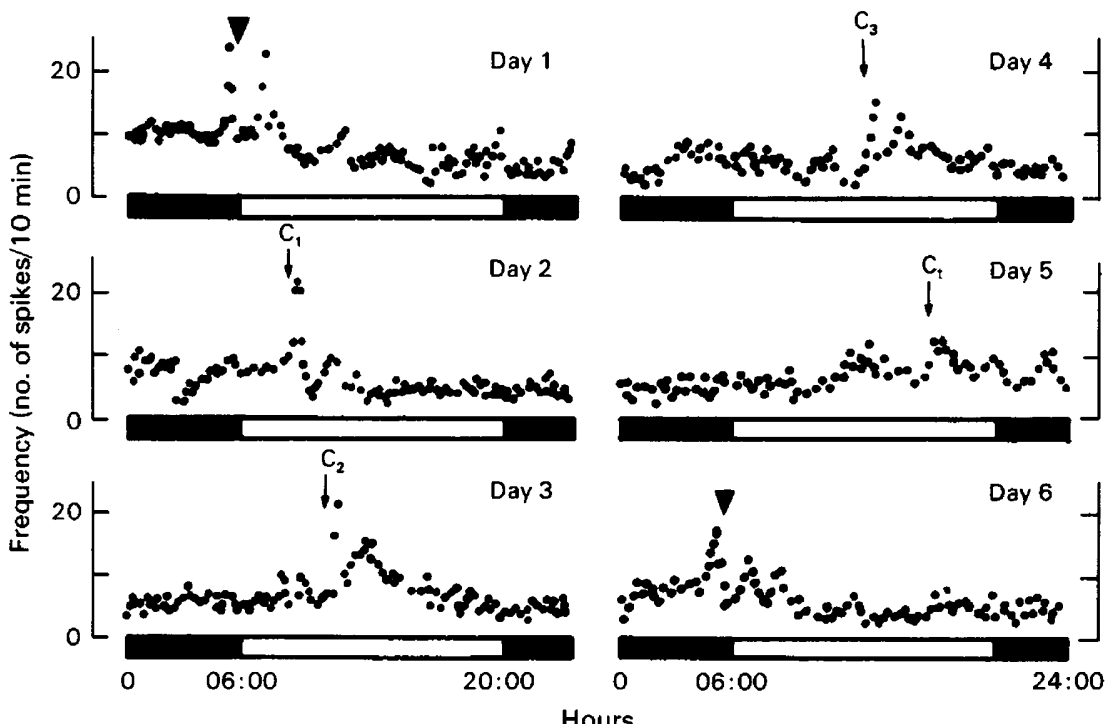

Text-fig. 2. Frequency histograms of electrical activity of the infundibulum throughout the normal laying cycle. Arrows indicate time of oviposition: triangles represent the estimated time of $\mathrm{C}_{1}$ ovulation of the clutch. Note the increased activity shortly before ovulation. The times of oviposition were: $\mathrm{C}_{1}, 08: 34 \mathrm{~h} ; \mathrm{C}_{2}, 10: 40 \mathrm{~h} ; \mathrm{C}_{3}, 12: 27 \mathrm{~h} ; \mathrm{C}_{\mathrm{t}}, 16: 25 \mathrm{~h}$. Oviposition of the fourth (terminal) egg of the previous clutch was at $17: 15 \mathrm{~h}$ and of the first egg of the next clutch at 08:09 h. 
the $C_{1}$ ovulation and then decreasing to low levels. After a pause day this hen laid the $C_{1}$ egg at 08:26 h and laid 7 more eggs for 7 consecutive days. The terminal $\left(C_{8}=C_{t}\right)$ egg of this clutch was laid at 18:04 h. When progesterone was injected $14 \mathrm{~h}$ before the predicted $\mathrm{C}_{1}$ ovulation, the $\mathrm{C}_{1}$ ovulation was advanced by about $6 \mathrm{~h}$ (Text-fig. 3). The patterns of electrical activity observed in association with the induced ovulation were similar to those of the spontaneous $\mathrm{C}_{1}$ ovulation of the previous clutch, although the frequency was lower than that found in the previous clutch. A sharp increase in the frequency of electrical activity of the infundibulum occurred about $15 \mathrm{~min}$ before the induced $\mathrm{C}_{1}$ ovulation. The preovulatory increase in the frequency of infundibular and uterine electrical activity was advanced in relation to premature ovulation in another 3 hens which were examined (data not shown).

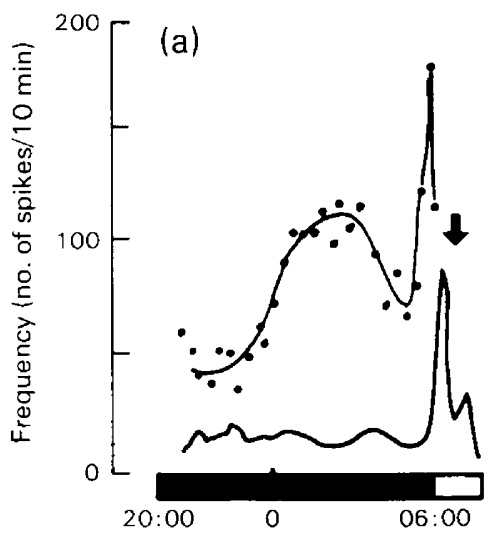

(b)

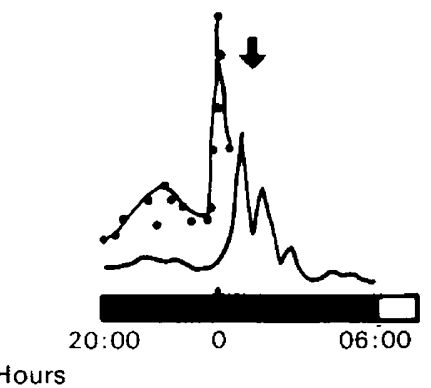

Text-fig. 3. Frequency histograms of electrical activity of the infundibulum (lower tracing) and the uterus (upper tracing) in relation to (a) the spontaneous $C_{1}$ ovulation and (b) the induced $C_{1}$ ovulation. Times of ovulation (arrows) were determined by the transient but marked increase in the frequency of the uterine electrical activity.

\section{Discussion}

The present study demonstrated marked changes in electrical activity of the infundibulum shortly before ovulation: during most of the ovulatory cycle only low-frequency activity was observed, but within $1 \mathrm{~h}$ before ovulation, intermittent bursts of spike potentials were observed and the frequency of the potentials increased. This pattern of the activity was advanced in relation to the time of induced ovulation. The infundibulum becomes extremely active at ovulation when the fimbria which surround the abdominal ostium becomes extended as the result of vascular engorgement and muscle fibres in the fimbria and in the ligament contract (Aitken, 1971). Although the fimbria may play the most important role in uptake of the shed ovum into the oviduct, the neck region of the infundibulum (the recording site of electrical activity) also plays a part. Observations on coeliotomized hens (unpublished) have shown that not only the fimbria but also other parts of the infundibulum become active and extend to surround the shed ovum. Although the propagation of electrical activity is very rapid in the smooth muscle of the oviduct, the magnum and the isthmus showed low activity (Shimada, 1978) when the infundibulum was exhibiting high electrical activity before the time of ovulation. Severance of the magnum-isthmus junction did not affect ovulation, engulfment of the shed ovum by the infundibulum or uterine electrical activity (Shimada, 1979). Accordingly, the increase in electrical activity of the infundibulum before ovulation may not depend upon the 
activity of the rest of the oviduct but may be related to the activity of the infundibulum engulfing the shed ovum. Unexpectedly, at the time of ovulation there was a decrease in electrical activity of the infundibulum which was followed by an increased activity. Some hens exhibited low activity for a considerable period after ovulation; the reason for this quiescence remains unknown but may be related to the presence of the egg in the infundibulum. The subsequent increase in electrical activity of the infundibulum may indicate progression of the ovum as well as secreted materials from the mucosa of the infundibulum.

Double-peaked frequency changes in the electrical activity of the infundibulum about the time of ovulation were also observed in the magnum and the isthmus (Talo \& Kekäläinen, 1976; Shimada, 1978). These changes may be a common characteristic of the oviduct when the egg is moved through the segment examined.

We thank Dr Robert J. Etches for reviewing this manuscript. The study was partly supported by grants (Nos 556184 and 56480060) from the Ministry of Education, Science and Culture of Japan.

\section{References}

Aitken, R.N.C. (1971) The oviduct. In Physiology and Biochemistry of the Domestic Fowl, Ch. 53, pp. 1240-1249. Eds D. J. Bell \& B. M. Freeman. Academic Press, London.

Chen, T.W. \& Hawes, R.D. (1970) Genital tract motility in the domestic hen. Poultry Sci. 49, 640-649.

Crossley, J., Ayuy, A. \& Ferrando, G. (1975) Some physiological characteristics of motility in the in vivo avian oviduct. Biol. Reprod. 13, 495-498.

Crossley, J., Ferrando, G. \& Eiler, H. (1980) Distribution of adrenergic receptors in the domestic fowl oviduct. Poultry Sci. 59, 2332-2335.

Gilbert, A.B. (1971) Transport of egg through the oviduct and oviposition. In Physiology and Biochemistry of the Domestic Fowl, Ch. 56, pp. 1345-1352. Eds D. J. Bell \& B. M. Freeman. Academic Press, London.
Roche, M. \& Brard, E. (1978) Study of the motility of the avian oviduct with chronically implanted electrodes. J. Reprod. Fert. 53, 217-222.

Shimada, K. (1978) Electrical activity of the oviduct of the laying hen during egg transport. J. Reprod. Fert. 53, 223-230.

Shimada, K. (1979) Preovulatory spike bursts in hen uterus. Biol. Reprod. 20, 1105-1110.

Shimada, K. \& Asai, I. (1978) Uterine contraction during the ovulatory cycle of the hen. Biol. Reprod. 19, 1057-1062.

Talo, A. \& Kekäläinen, R. (1976) Ovum promotes its own transport in the oviduct of the Japanese quail. Biol. Reprod. 14, 186-189.

Verma, O.P., Prasad, B.K. \& Slaughter, J. (1976) Avian oviduct motility induced by prostaglandin $E_{1}$. Prostaglandins 12, 217-227. 